\title{
Regional land use analysis: The development of operational tools
}

\author{
J.J. Stoorvogel' and J.M. Antle 2
}

\begin{abstract}
Regional land use analysis plays a key role in the analysis of agricultural policies. However, few operational tools for regional land use analysis are available. Current developments in regionat land use analysis are rather ad hoc. More generic methodologies are required to effectively answer questions by policymakers. The analysis may require methods to explore, project and predict agricultural land use. An all-encompassing methodology seems unrealistic. A toolbox for regional land use analysis is proposed. The tools (including, e.g., data base management systems, GIS and economic models) can be linked in such a way that they can carry out the specific analysis required for the specific conditions of stakeholders. To facilitate linkages between the different tools, data standards need to be developed for both biophysical as well as economic data. Discussions with stakeholders in an early phase of the analysis may set priorities and determine the selection of tools. Results of the analysis need to be presented in such a way that they are appealing to the stakeholders. Only then can they be transferred effectively.
\end{abstract}

\section{INTRODUCTION}

With an increasing pressure on land, it becomes ever more important for policymakers to keep track of land use changes and, if necessary, to influence these changes according to their specific objectives through agricultural policies. Agricultural policies can be used to avoid land use conflicts, minimize adverse environmental effects and maintain or in crease agricultural production. The main question in the development of agricultural policies is to know possible changes and options for land use and to predict the effect of agricultural policies through re- spectively projective, explorative and predictive land use studies. In this paper, we will discuss regional land use analysis as a tool for policymakers and focus on policy-oriented, forward-looking studies. A major question that we will pose is whether we have tools available that are operational and, if not, what is required to develop them?

Several methodologies have been developed in the past to project (e.g. CLUE by De Koning et al. 1999), explore (e.g. SysNet by Hoanh et al. 1998; SOLUS by Bouman et at. 1999), and predict (e.g. Tradeoff Analysis model by Crissman et al. 1998) agricultural land use. However, the process of

\footnotetext{
'Laboratory of Soil Science and Geology, Wageningen University, Duivendaal 1, P.O. Box 37, 6700 AA Wageningen, The Netherlands. E-mail: jetse.stoorvogel@bodlan.beng.wau.nt

2Department of Agricultural Economics and Economics, Monatana State University, Bozeman MT59717, USA
} 
defining and selecting policies does not end with the projection of trends nor with the exploration of opportunities. To effectively develop, select and implement agricultural policies we need to project. explore and predict agricultural land use (Van Ittersum et al. 1998). An all-encompassing methodology seems unrealistic. Consequently, we need a range of methodologies that serve different purposes and that apply to different situations. Despite many commonalties, the available methodologies are based on very different procedures. Some apply linear programming techniques (e.g., SysNet and SOLUS), others are based on statistical techniques (e.g., CLUE), while others use simulation models (e.g., the Tradeoff Analysis model). Current developments in regional land use analysis can be described as being rather ad hoc since many methodologies are developed for specific situations. As a result, they are not very generic. Basic concepts and procedures are available and each particular project dealing with regional land use analysis takes a number of techniques from the shelf and starts creating their own application.

The development of a user shell over different crop growth simulation models (Jones et al. 1998) together with the appropriate data standards (Hunt and White 2000) has plaid a crucial role in the rapid developments in the field of land use analysis at the field level. To gear the development of tools for regional land use analysis, a similar thrust needs to be made in which the International Consortium for Agricultural Systems Applications (Ritchie 1995) can play an important role. Standards for database formats need to be developed together with more generic versions of regional land use analysis tools. Are there opportunities? The requirements are certainly different and probably more diverse than data standards for crop growth simulation models. In this paper, we would like to explore the opportunities for the development of operational tools. First, we describe a number of basic concepts, then we discuss regional land use analysis by way of a number of case studies.

\section{BASIC CONCEPTS}

\section{Actors and Stakeholders}

It is impossible to study regional land use without considering the people and institutions that play a role in the region. The most successful land use studies are being carried out in close interaction with the people and institutions involved. In this paper, we distinguish between stakeholders and actors. The stakeholders are the parties directly interested in the outcomes of the study. They will be the future users of the results of the study or the methodology under development. Despite studies that are strictly scientific exercises, studies (e.g., in development projects) are (or should be) shaped around the objectives of the stakeholders.' The actors, on the other hand, are all the people in the region that to some extent play a role in the agricultural sector. Farmers, for example, make land alfocation and land management decisions and, as a result, play a key role in agricultural land use. They are, however, not the target group that will use directly the results and methodologies of regional land use studies and, consequently, they are referred to as actors and not as stakeholders. Many tools for regional land use analysis are developed to answer questions raised by regional or national politicians and as a result they are among the main stakeholders of the study.

\section{Model Objectives}

Policy-oriented, regional land-use studies are often sub-divided on the basis of their objectives into explorative, projective and predictive models Nan Ittersum et al. 1999). Explorative studies determine what can be done where and when. Agricultural land use is restricted by numerous biophysical and socioeconomic constraints. As a result, we cannot do everything everywhere at any time. The window of opportunities, hereafter referred to as the opportunity space, includes the range of all possible options. It includes outcomes of decisions, which are not perceived by the stakeholder or not considered viable in terms of their ability to access them. In contrast to the opportunity space, there is the decision space. which refers to the range and nature of the options the stakeholders consider being relevant and potentially achievable (Lemon 1999). Ideally, decision space and opportunity space coincide, but reatity shows that the two spaces only partially overlap. As a result three specific situations are identified by the partially overlapping opportunity space $A$ and the decision space B (schematically represented in Figure 1).

AnB: Options that are viable (within the opportunity space $A)$ and that are considered relevant and potentially viable by the stakeholder(s) (within the decision space $\mathbf{B}$ ). 


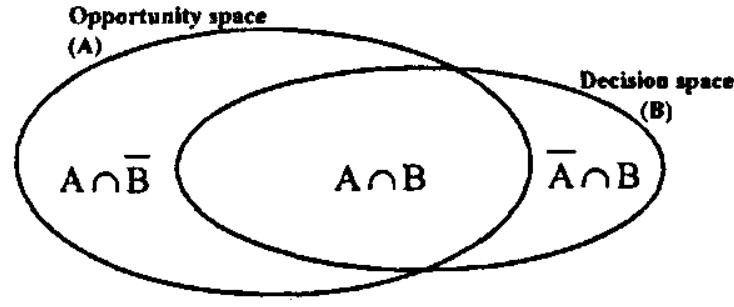

Figure 1. Schematic representation of the overlapping opportunity space and decision space.

$A \cap \bar{B}:$ Options that are viable (within the opportunity space A) but that are not considered to be relevant and potentially viable by the stakeholder(s) (outside the decision space B).

$\bar{A} \cap B:$ Options that are considered to be relevant and potentially viable by the stakeholder(s) (within the decision space B), but that are not viable (outside the opportunity space A).

Explorative land use studies show the opportunity space to the stakeholders. It pinpoints to viable options the stakeholders are not aware of and to options considered relevant by the stakeholders that are, in reality, not viable. If the results of explorative land use studies are transferred successfully to the stakeholder, the decision space and the opportunity space will coincide. It is important to realize that the decision space plays a role at different scale levels. The decision space of farmers whilst taking their land allocation decisions is composed of the existing or known land use systems and technologies. The introduction of new crops or alternative technologies will broaden the scope of the farmers and as a result the decision space. Similarly, farmer schools may train farmers in the fact that certain farm practices seriously degrade the farms' resources and as a result are not feasible in the long term. Each of the actors take decisions and for each of the decisions they look in their specific decision space.

In the context of this paper, we focus on the stakeholders of the regional land-use analysis. What contains the decision space of the policymaker? It is a wide range of policy alternatives as well as alternative land use scenarios.

Projective models study past land cover and land use changes in relation to biophysical and socioeconomic parameters and project future trends given certain changes in the parameters. Due to their inherent characteristics, projective models are generally unable to capture abrupt changes in agricultural land use due to, for example, natural disasters, the collapse of markets, or the introduction of completely new agricultural technologies. Nevertheless, projective studies are extremely important to policymakers since they indicate the possible changes without interventions. Policymakers can subsequently decide whether these trends are desired or not and whether they want to intervene with agricultural policies.

Finally, predictive models have been developed that actually predict land use changes as a result of agricultural policies. Predictive land use studies answer scenario type 'What-if' questions and indicate where agricultural land use will move within the opportunity space after implementing a certain agricultural policy. Due to uncertainties in the prognoses of many drivers governing land use change, predictive models can only be applied with a short time horizon.

These three groups of models have a large complimentary value. Explorative models identify the possibilities in the opportunity space, projective models indicate what will happen to agricultural land use if trends continue, and the projective models define the likely impact of agricultural policy.

\section{Policy Instruments}

Stakeholders have an array of alternative policy instruments available that allow them to move agricultural land use within the opportunity space according to their specific objectives. A large number of policy instruments can be identified. Some examples from Lemon (1999), Van Keulen et al. (1998) and Wiebe and Meinzen-Dick (1998) are give below.

\section{Macro-economic policies.}

- Price liberalization

- Removal of quantitative and administrative trade barriers

- Redefining the role of the government

Price policies.

- Subsidies on agricultural inputs and/or products

- Price support that guaranties prices for agricultural products

Regulatory irstruments. 
- Environmental regulation for pesticide and/or nutrient emissions

- Banning of certain agricultural inputs (pesticides)

\section{Instruments focused on the farmer.}

- Management support through for example the extension service

- Technological support that enables farms to a better access to production technologies

- Economic support enabling farmers to obtain credits or crop insurance

- Land tenure

Agricultural policies, typically, are composed out of one or more policy instruments. Regional land use studies should be able to indicate the (possible) changes that one or a combination of policies will induce. Besides considering the possible consequences of agricultural policies, stakeholders have to look for policies that are socially acceptable and economicaliy viable. Regulatory instruments, for example, are only successful if they can be enforced. They will, therefore, not be a feasible solution in many developing countries.

\section{Tools for Regional Land Use Analysis}

For the development of methodologies for regional land use analysis we have a large number of tools available that can be used to reach our objectives. We distinguish between methodologies and tools. For a specific objective we may need a methodology that comprises a number of tools. Tools for regional land use analysis include programming models, statistical models, and simulation models, but also tools for data management (data base management systems, geographical information systems), biophysical models to estimate crop production and solute flows, and tools for the estimation of input parameters for cropping systems. Methodologies comprise a number of these tools that are linked in a specific way to serve the objective of the study.

\section{THE IMPLEMENTATION OF REGIONAL LAND USE ANALYSIS}

Researchers face a number of challenges in implementing regional land use analysis. Despite the widespread acceptance to aim for sustainable agricultural land use, a scientific consensus is lacking on how the economic, environmental, and public health impacts of agricultural policies can be quantified and assessed (Crissman et al. 1998). Analysis of these complex, interrelated issues raises a number of difficult theoretical and methodological problems. Regional land use analysis involves issues addressed by various fields of science and thus requires a multidisciplinary approach. Overcoming disciplinary biases and establishing effective inter-disciplinary communication is a continuing challenge. Another major issue deals with the validation of the methodologies for regional land use analysis. Validation is only possible on the basis of past land use changes, and those data often form the basis for the development of land use analysis. As a result, one can question how these methodologies can be evaluated in an objective manner.

\section{General Structure}

Regional land use analysis can only be carried out through intensive multi-disciplinary research. Crissman et al. (1998) defined an organizing principal and conceptual model for the design and organization of multi-disciplinary research projects. Although they focused on the quantification and assessment of competing objectives in agricultural production systems in terms of trade-offs, the principles seem to have more general validity. This process is illustrated in Figure 2 and comprises three major steps:

1. At the start of a project a joint effort by researchers and stakeholders is required to set research priorities. Within this priority setting it is important that researchers become aware of the opportunity space, the current trends and possible changes induced by agricultural policy. This has to be done in extensive brainstorming sessions and a review of past studies. The major objectives of the study in combination with available resources (including existing data) will determine the focus of research.

2. If the outline of the general objectives is defined, the project can be designed and implemented. This includes the selection of the relevant disciplines to quantify the processes that are considered to be of major importance in the first step. It will also include the selection of the appropriate tools. Before the models can be implemented data need to be gathered. In most cases, data gathering is probably the most limiting factor. Policies need to be planned on a short notice, leaving little data for extensive data 


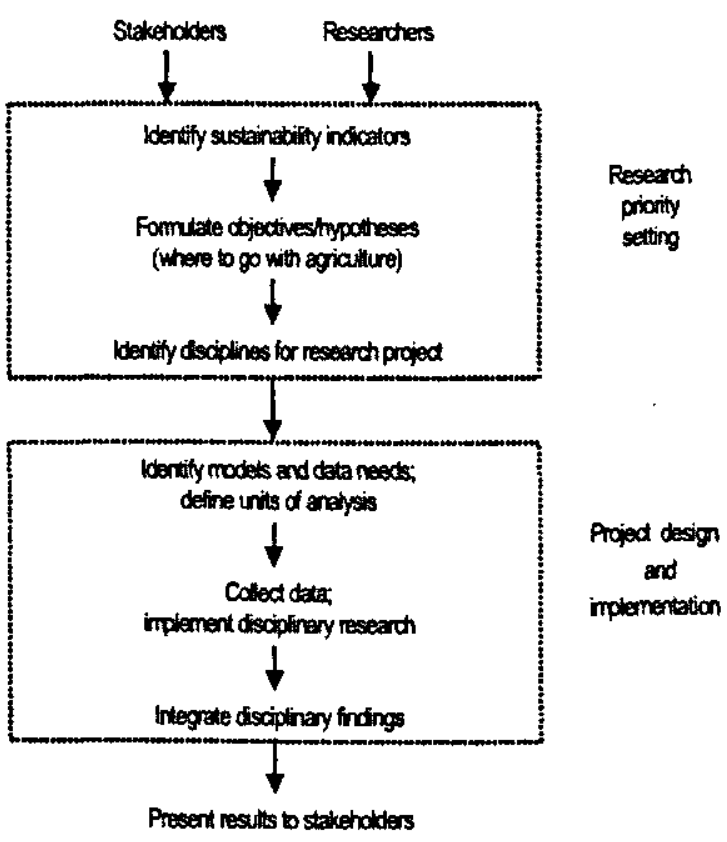

Figure 2. A structure for the implementation of regional land use analysis.

collection efforts. Finally, special efforts are necessary to integrate disciplinary findings.

3. The results need to be presented in such a way that they are understandable and appealing to the stakeholders. Specific concepts like tradeoff curves (Antle et al. 1998) may be especially useful since they link up easily with the way policymakers are thinking. New developments in Information and Communication Technology (ICT) can be used to transfer the results to the relevant stakeholders.

Although the above scheme seems a rather linear and static approach to regional land use analysis, its strength can be found in a flexible application with numerous feed back loops.

A critical element in each research program is for all disciplines to agree upon basic spatial and temporal units of analysis. Different disciplines operate traditionally at different scale levels, or use different criteria to identify spatial units or temporal intervals. Typically, larger regional studies work at different hierarchical levels. A larger number of processes take place at large scales (crop growth, pesticide leaching) while others take place at small scales (policy issues). These processes need to be studied at the corresponding scale level. As a result, different components of the analysis use different units of analysis, thus procedures need to be defined to link the different analyses. Agricultural policies deal with relatively large units of analysis. All researchers must address the aggregation problem, i.e., the problem of combining heterogeneous small units into larger units, if their data and results are to be useful for policy analysis. While much emphasis has been placed on the problem of spatial aggregation, similar problems arise in the time dimension.

Disciplinary research typically operates in a format dictated by disciplinary orientation and generates data intended to satisfy disciplinary objectives. This disciplinary orientation of research leads to a situation in which various pieces of the scientific puzzle are investigated without regard to the fitting together of those pieces into the larger picture that is required for policy analysis. The larger the spatial or temporal scale, the more complex becomes the process of exploring and predicting agricultural land use. Analysis at the regional or national scale is even more difficult than analysis at smaller scales, such as a watershed.

\section{Data Standards}

Data standards are the key elements for the success of methodologies for regional land use analysis. Only with appropriate data standards the various tools are able to communicate. The data standards applied in the Decision Support System for Agrotechnology Transfer (DSSAT; Jones et al. 1998) are an excellent example to illustrate the importance of data standards. However, DSSAT focuses on crop growth simulation models only and the data are limited to the biophysical environment of crop growth. If data standards are not available, data need to be 'translated' before tools can communicate. The transiation programs make the linkages of tools a rather cumbersome undertaking. Regional land use analysis requires data standards for a large number of disciplinary data sets and they have to be scale independent. As a result, the requisites are much more demanding. The initial investment may, however, pay-off in a later stage when it becomes relatively easy to link the different tools. Numerous efforts have been done in the past to standardize soil and climatic data. However, little has been done for the storage of economic data.

\section{Model Structure}

Despite the fact that there is a whole array of models for regional tand use analysis, there are four major groups: statistical models, econometric 
models, programming models, and simulation models. It will be extremely difficult to make a generic structure for each of these models. Nevertheless, the tools within each group are rather similar. Programming models applied in, e.g. SysNet and SOLUS are similar in the concept that they have a certain LP-tableau with afternative land use systems, a set of constraints in terms of resources, and an objective function that maximizes net income of the region. Variations, however, do exist. SysNet and SOLUS do not consider the actual farm structure such as USTED. SysNet and USTED on the other hand do not consider price elasticity. The major question is whether we can generalize the LP tableau in such a way that it is applicable in the different case studies.

\section{Toolbox}

A toolbox for regional land use analysis will not only be a large bucket with different tools. Tools will need to be adapted that they can communicate with each other. This can be done through the definition of data standards (as done for crop growth simulation models by Hunt and White (2000)), but also through a user shell that transiates the output from one tool to the input of another, or through a combination of both. The concept of a toolbox is relevant if a number of basic criteria are fulfilled. First of all, data standards are required that are used by all the tools in the toolbox. Secondly, procedures are necessary to bridge the gaps between different hierarchical scale levels. Finally, the appropriate tools are necessary to present the results in a format that the stakeholders can understand them. If the concept works properly, 'plug and play' technology can be applied. Different tools can be combined without requiring any adaptation to the tools themselves. The output of one tool automatically functions as the input for another.

\section{CASE STUDIES FOR REGIONAL LAND USE ANALYSIS}

To iliustrate the possibilities of regional land use, studies and efforts that has been accomplished in the past a number of case studies will be discussed.

\section{Case 1: Regression Models}

Most regional land use analysis look forward in their analysis. However, there is a lot to be learnt from the past. Regression models analyze past land use and project the trends to the future. Although we can use rather straightforward statistical techniques. we can also make use of more advanced procedures. De Koning et al. (1999) present a multi-scale modeling approach of land use change dynamics in Ecuador on the basis of a regression model. The analysis allows for the determination of 'hot-spots' with dynamic changes, but it also allows the determination of drivers behind land use change at different scale levels. The methodology, denominated CLUE (Conversion of Land Use and its Effects), has been applied in case studies for Costa Rica, Ecuador and China.

The methodology is based on a statistical analysis of past land use. Land use changes are analyzed and correlated with a number of potential drivers for land use changes such as biophysical and socio-economic characteristics.

Since relations can be specific to a certain scale level, the analysis is carried out for different levels of aggregation. The lowest level of aggregation, i.e., the most detailed scale level, is dictated by the data available for the study area. Data availability varies between different countries and regions and the methodology has to be adapted accordingly.

The methodology clearly illustrates what can be done through the projection of past land use towards the future. This kind of projective analysis is crucial since it may pinpoint to specific problems that may arise in the future and to areas that are most susceptible to present problems. In addition, it indicates the major drivers for these changes. These drivers may indicate which policies are most likely to be successful to turn the tide.

\section{Case 2: Farm Household Models}

Farm household models are frequently applied for regional land use analysis (see for example Kruseman and Blade 1998). The question they try to answer is how farming systems will react to regional policies. The almost infinite number of farms within a region is generalized in a limited number of 'representative' farm types. These farm types are described in detail and analyzed inrough a scenario type study answering 'What-if' questions. The most commonly applied technique for the farm household models are (multiple goal) linear programming techniques. It is a relatively straightforward way to tackle the scale problems. Land use decisions are mostly taken at the farm level, and since it is impossible to study each 
individual farm, results are based on generalized farm types. The question - i.e., what is the effect of agricultural policies on the agricultural sector - can only be answered after aggregating the results to the regional level. In the case of linear programming models this is in most cases done in a linear way. The main constraint of these models is that the interaction between farming systems is not considered and they assume a certain 'optimal' behavior of farmers. This is certainly not always the case.

\section{Case 3: Regional Optimization Model}

Regional optimization models have been developed in different forms. Some applications show the direct link with the farm household models and incorporate the farm level (Schipper et al. 1995), others consider a large region as one large farm (WRR 1992). The potential impacts of such a generalization were found to be considerable (lansen and Stoorvogel 1998). Almost all models share the same objective: explore possible changes in agriculture land use as a result of changes in the biophysical or socio-economic environment. These changes can be induced by agricultural policies. Note that most applications of regional optimization models are already a combination of a number of tools. Resources are spatially explicit and stored in a GIS environment, inputloutput matrices describe land use systems and the optimization of agricultural land use takes place by a (linear) programming model. The models can work at different levels of aggregation. USTED, for example, considers actual constraints at the farm level by optimizing for different farm types. SOLUS and SysNet work at a higher aggregation level that does not include the actual farm structure.

\section{Case 4: Agricultural Sector Models}

Although many factors need to be considered when analyzing agricultural policies, we may identify situations where complex methodologies simply reflect simple production functions. Complexity should not be a goal, we have to be realistic and need to include factors in our models that play a role for the specific analysis. The farm level may, therefore, be left out at higher levels of analysis. Agricultural sector models do exactly that and analyze the agricultural sector as a whole. In many cases, the analysis is based on general relationships found in the agricultural sector. The Multi-Level Analysis tool for the Agricultural Sector (Mata) developed by
Gerard et al. (1994) is a partial equilibrium model developed to evaluate response trends on agricultural production and food consumption as a result of policy changes. An obvious disadvantage is that the models are not spatially explicit. As a result it is extremely difficult to link this kind of models to biophysical models to determine, for example, the environmental effect of agricultural activities.

\section{Case 5: Simulation Model for Agricultural Decision Making}

Land allocation and management decisions are taken at the farm level. As a result it is important to consider this level in a land use analysis tool, even at the regional level. If we want to evaluate the expected changes in land use or, as done in a study by Antle et al. (1998) trade-offs between economics, environment and human health, we can not discard this level of analysis, even if it is a heavy burden on data requirements.

Political pressure to identify a set of sustainable production technologies implies that there must be some means of ranking the importance of the various impacts. Ranking technologies according to multiple criteria requires a method of converting these criteria to a common unit of analysis. One approach is to utilize multi-attribute decision models, i.e., to assign weights to the alternative outcomes. This raises the question of what weights to use. The economic approach to this problem is to convert alt impacts to monetary terms and to use this information to conduct a benefit-cost analysis. However, despite decades of research on valuation of environmental and health outcomes by environmental and health economists, a scientific consensus on valuation methods is lacking, and data for valuation of most environmental and health impacts are not readily available, particularly in developing countries. Even when monetary valuations are feasible, their acceptance by the public or by policy decision makers is often questionable (e.g., in the United States, federal government agencies may not accept results from contingent valuation studies, see Belzer 1999). The philosophy underlying the Tradeof Model is that a more useful approach to informing the policy decision making process is to establish a sound scientific basis for quantifying trade-offs that exist with alternative production systems, without attempting to value impacts for benefit-cost analysis. 


\section{DISCUSSION AND CONCLUSIONS}

The five cases illustrate the very different ways that regional land use analysis can be carried out. All the methods have pro and cons and are based on different techniques. The variety in tools is a logical consequence of differences in questions that need to be answered and in the boundary conditions that are set during the development of the methods. The development of operational tools is therefore not restricted to the development of a single methodology. Each of the different methodologies can be less specific to the situation and developed in a more generic way. This facilitates the application in other studies. Only if this last, crucial, but difficult task is accomplished, can we actually say that tools for regional land use analysis are available for specific applica. tions. Currently, few operational methodologies are available for regional land use analysis. Most methodologies are very specific for the specific conditions in which they have been developed. Methodologies for regional land use analysis can only become operational if a number of aspects are kept in mind:

- Stakeholders play a key role in the formulation of research. They are the future users of the results and need to be consulted in an early stage of the project. Ideally they are the actual initiators of the project.

- The analysis of regional land use requires a multi-disciplinary research effort. A more holistic view in disciplinary research is required to enable the linkages. Disciplinary research to study specific components of the system will always play a key role in regional land use analysis.

- Data limitations are often a heavy burden on regional projects. During the development of methodologies, minimum data sets need to be defined that allow users to easily identify the necessary data collection.

- Develop a toolbox for regional land use analysis. For the toolbox to become effective, 'plug and play' technology needs to be developed. This includes data standards for both biophysical and socio-economic data but also requires the development of more generic tools.

- More attention to the presentation of results making use of current ICT developments but certainly the needs by policymakers.

\section{ACKNOWLEDGEMENTS}

The Netherlands Academy of Arts and Sciences funds the Research of Dr Stoorvogel.

\section{REFERENCES}

Antle J M, Capalbo S M. Crissman C C (1998) Tradeoffs in policy analysis: conceptual foundations and disciplinary integration. Pages 21-40 in Crissman C C. Antle I M. Capalbo S M (Eds.) Economic. environmental, and health tradeofis in agriculture: pesticides and the sustainability of Andean potato production. Kluwer Academic Publishers. Dordrecht, The Netherlands.

Belzer R B (1999) "HACCP Principles for Regulatory Analysis." In L Unnevehr, ed., The Economics of HACCP: Studies of Costs and Benefits. Eagan Press, St Paul MN.

Bouman B A $M$, lansen $H$ G P. Schipper $R$ A, Nieuwenhuyse A, Hengsdijk H, Bouma J (1999) A framework for integrated biophysical and economic land use analysis at different scales. Agriculture, Ecosystems and Environment 75:55. 73.

Crissman C C. Antle J M, Capalbo S M (Eds.) (1998) Economic, environmental, and health tradeoffs in agriculture: pesticides and the sustainability of Andean potato production. Kluwer Academic Publishers, Dordrecht, The Netherlands. 281 p.

De Koning G H J, Verburg P H, Veldkamp A, Fresco L O (1999) Multi-scale modelling of land use change dynamics in Ecuador. Agric. Systems 61:77-93.

Deybe D (1998) Can agricuitural sector models be a tool for policy formulation? An application for the case of Burkina Faso. Agric. Systems 58:367-380.

FAO (1993) Guidelines for land-use planning. FAO Development Series 1. FAO. Rome.

Gerard F, Boussard I M. Deybe D (1994) MATA: Prototype of multilevel analysis tool. URPA Working Paper No. 23. CIRAD, Paris, France.

Hoanh C T, Roetter R, Jansen D M. Aggarwal P K, Lansigan F P. Lai N X, Bakar I A, Tawang A (1998) Generalizing SysNet methodologies for land use planning at the sub-national level. Pages 41.56 in Roetter R, Hoanh C T, Luat N V, Van Ittersum $M$ K. Van Laar H H (Eds.) Exchange of methodologies in land use planning. SysNet Research Paper Series No. 1. IRRI, Los Baños. Philippines.

Hunt L A, White / (2000) Agronomic data: Advances in documentation and protocols for exchange and use. In Proceedings - Third International 
Symposium on Systems Approaches for Agricultural Development (CD-ROM computer filej. International Potato Center (CIP). Lima, Peru.

Hunt L A, Jones I W. Hoogenboom G, Godwin D C. Singh U. Pickering N, Thornton P K, Boote K J, Ritchie J $T$ (1994) General input and output files structures for crop simulation models. Pages 35-73 in Uhlir P F. Carter G C (Eds.) Crop modeling and related environmental data: $A$ focus on applications for arid and semiarid regions in developing countries. CODATA, Paris, France.

Jansen H G P. Stoorvogel J J (1998) Quantification of aggregation bias in regional agricultural land use model: application to Guácimo county, Costa Rica. Agric. Systems 58: 417-439.

Jones J W. Tsuji G Y. Hoogenboom G, Hunt L A, Thornton $P K$. Wilkens $P$ W. Imamura D T, Bowen W T. Singh U (1998) Decision support system for agrotechnology transfer: DSSAT v3. Pages 157177 in Tsuji G Y. Hoogenboom G. Thomton P K (Eds.) Understanding options for agricultural production. Kluwer Academic Publishers, Dordrecht, The Netherlands.

Kruseman G, Bade J (1998) Agrarian policies for sustainable land use: Bio-economic modelling to assess the effectiveness of policy instruments. Agric. Systems 58: 465-481.

Lemon $M$ (1999) Exploring environmental change using an integrative method. Gordon and Breach Science Publishers, Amsterdam.
Ritchie I T (1995) International Consortium for Agricultural Systems Applications (ICASA): Establishment and purpose. Agric. Systems 49:329-335.

Roetter R, Hoanh C T, Luat N V, Van Inersum M K, Van Laar $H \quad H$ (Eds.) (1998) Exchange of methodologies in land use planning. SysNet Research Paper Series No. 1, International Rice Research Institute, Los Baños, Philippines. 153 p.

Schipper R A. Jansen D M. Stoorvogel I / (1995) Subregional linear programming modets in lands use analysis: a case study of the Neguev settlement, Costa Rica. Netherlands bournal of Agricultural Science 43: 83-109.

Van Ittersum M K, Rabbinge R, Van Latesteijn H C (1998) Exploratory land use studies and their role in strategic policy making. Agric. Systems 58: $309-$ 330.

Van Keulen H. Kuyvenhoven A, Ruben R (1998) Sustainable land use and food security in developing countries: DLV's approach to policy suppor. Agric. Systems 58: 285-307.

Wiebe K D. Meinzen-Dick R (1998) Property rights as policy toois for sustainable development. Land Use Policy 15: 203-215.

WRR (1992) Ground for choices, four perspectives for the rural areas in the European Community. Reports to the government no. 42. Sdu Uitgeverij, Den Haag. 